\title{
pH-Dependent Structural Dynamics of Cathepsin D-Family Aspartic Peptidase of Clonorchis sinensis
}

\author{
Jung-Mi Kang ${ }^{1,2}$, Hương Giang Lê ${ }^{1,2}$, Byoung-Kuk Na ${ }^{1,2} \mathbb{D}$ and Won Gi Yoo ${ }^{1,2, *(D)}$ \\ 1 Department of Parasitology and Tropical Medicine, Institute of Health Sciences, Gyeongsang National \\ University College of Medicine, Jinju 52727, Korea; jmkang@gnu.ac.kr (J.-M.K.); \\ gianglee291994@gmail.com (H.G.L.); bkna@gnu.ac.kr (B.-K.N.) \\ 2 Department of Convergence Medical Science, Gyeongsang National University, Jinju 52727, Korea \\ * Correspondence: wgyoo@gnu.ac.kr; Tel.: +82-55-772-8101
}

Citation: Kang, J.-M.; Lê, H.G.; Na, B.-K.; Yoo, W.G. pH-Dependent Structural Dynamics of Cathepsin D-Family Aspartic Peptidase of Clonorchis sinensis. Pathogens 2021, 10, 1128. https://doi.org/10.3390/ pathogens10091128

Academic Editor: Petr Horák

Received: 12 May 2021

Accepted: 29 August 2021

Published: 2 September 2021

Publisher's Note: MDPI stays neutral with regard to jurisdictional claims in published maps and institutional affiliations.

Copyright: (c) 2021 by the authors. Licensee MDPI, Basel, Switzerland. This article is an open access article distributed under the terms and conditions of the Creative Commons Attribution (CC BY) license (https:// creativecommons.org/licenses/by/ $4.0 /)$.

\begin{abstract}
Cathepsin D (CatD; EC 3.4.23.5) family peptidases of parasitic organisms are regarded as potential drug targets as they play critical roles in the physiology and pathobiology of parasites. Previously, we characterized the biochemical features of cathepsin D isozyme 2 (CatD2) in the carcinogenic liver fluke Clonorchis sinensis (CsCatD2). In this study, we performed all-atomic molecular dynamics simulations by applying different systems for the ligand-free/bound forms under neutral and acidic conditions to investigate the $\mathrm{pH}$-dependent structural alterations and associated functional changes in CsCatD2. CsCatD2 showed several distinctive characteristics as follows: (1) acidic $\mathrm{pH}$ caused major conformational transitions from open to closed state in this enzyme; (2) during 30-36-ns simulations, acidic $\mathrm{pH}$ contributed significantly to the formation of rigid $\beta$-sheets around the catalytic residue Asp 219 , higher occupancy (0\% to 99\%) of hydrogen bond than that of $\mathrm{Asp}_{33}$, and enhanced stabilization of the CsCatD2-inhibtor complex; (3) neutral $\mathrm{pH}$-induced displacement of the N-terminal part to hinder the accessibility of the active site and open allosteric site of this enzyme; and (4) the flap dynamics metrics, including distance $\left(d_{1}\right)$, TriC $\alpha$ angles $\left(\theta_{1}\right.$ and $\left.\theta_{2}\right)$, and dihedral angle $(\phi)$, account for the asymmetrical twisting motion of the active site of this enzyme. These findings provide an in-depth understanding of the $\mathrm{pH}$-dependent structural dynamics of free and bound forms of CsCatD2 and basic information for the rational design of an inhibitor as a drug targeting parasitic CatD.
\end{abstract}

Keywords: Clonorchis sinensis; cathepsin D; aspartic peptidase; molecular dynamics simulation; $\mathrm{pH}$ effect; flap dynamics

\section{Introduction}

Clonorchiasis is a parasitic disease caused by the liver fluke Clonorchis sinensis. This parasite is prevalent in far East Asian countries, including China, Korea, and Northern Vietnam, and it is reported to infect approximately 35 million people worldwide [1]. Infections in humans usually occur because of consumption of raw or inadequately cooked freshwater fish carrying the $C$. sinensis metacercariae. After the infection, the metacercariae exist in the duodenum of the human body and the juvenile worms migrate through the ampulla of Vater to reach the common bile duct. C. sinensis worms induce a series of pathological changes in the bile duct, resulting in epithelial hyperplasia, periductal fibrosis, obstructive jaundice, dyspepsia, and cirrhosis of the liver [2]. Chronic clonorchiasis can induce diverse complications, such as periductal inflammation, fibrosis, cholangitis, cholelithiasis, and cholangiectasis $[1,3,4]$. C. sinensis has been classified by the World Health Organization as Group I biocarcinogen that promotes cholangiocarcinoma in humans [5].

Peptidases of parasitic helminths are one of the most extensively studied molecules because of their pivotal pathobiological roles in the physiology and nutrition of parasites as well as host-parasite interactions [6-15]. Among various peptidases, cathepsin D (CatD; EC 3.4.23.5) is considered an attractive target for the design of vaccines or anthelminthic 
drugs [16-19], as it is an essential component for the degradation of the host hemoglobin or proteins within the gut of blood-feeding flukes [18,20-22]. Recently, we characterized the biochemical and immunological properties of two CatDs of $C$. sinensis, cathepsin D isozyme 1 (CsCatD1) and cathepsin D isozyme 2 (CsCatD2) [23]. CsCatD2 is likely to play an important role as a digestive enzyme as it is mainly expressed in the intestinal epithelial cells of $C$. sinensis adult worms. In light of its importance in parasite survival and nutrition, inhibition of the CsCatD2 may deliver an anti-clonorchiasis effect although the physiological role of CsCatD in C. sinensis has yet to be elucidated.

Enzyme-substrate binding is a dynamic process in which enzymes undergo structural changes, resulting in the disruption of chemical bonds in the substrates and/or formation of new ones to yield the end products [24]. The active site pocket of typical CatDs is covered by the $Y$ flap region (commonly known as the antiparallel $\beta$-sheet) that plays an important role in binding of the substrate [25]. Understanding the flap dynamics of CatDs is essential to gain an in-depth knowledge of the molecular aspects of enzyme-substrate interactions, particularly in $\mathrm{pH}$-dependent structural alterations of the enzyme. It may also provide crucial information for the design of optimized aspartic peptidase inhibitors as drugs targeting the CatDs of the parasite.

In this study, we performed all-atomic molecular dynamics (MD) simulations in the ligand-free and bound forms of the CsCatD2 homology models under acidic and neutral conditions to explore the molecular features of flap dynamics and study the $\mathrm{pH}$-induced structural alterations of CsCatD2.

\section{Results and Discussion}

\subsection{Homology Models and Features of Mature CsCatD2}

The models for free-CsCatD2 (CsCatD2 $2_{\text {free }}$ ) and bound-CsCatD2 (CsCatD2 ${ }_{\text {bound }}$ ) were built based on the experimental X-ray characterized structures of Ixodes ricinus cathepsin D 1 (IrCD1), without the inhibitor (Protein Data Bank (PDB) code: $5 n 7 n$ ) and in complex with the pepstatin (PDB code: 5n7q) from the tick I. ricinus (Figures S1 and S2). The IrCD1 structures were chosen as the best templates with an E-value of 4e-148, sequence similarity of $73 \%$ and coverage of $96 \%$ via the protein-Basic Local Alignment Search Tool (BLASTP) against the PDB database [26]. To generate the CsCatD2 ${ }_{\text {bound }}$ structure model, the pepstatin from the template (PDB code: $5 \mathrm{n} 7 \mathrm{q}$ ) was superimposed on the homology model of CsCatD2 during the modeling process. Mature CsCatD2 showed a conserved bilobed structure consisting of two antiparallel $\beta$-sheet domains packed against each other. The interdomain connects the $\mathrm{N}$ - and C-terminal domains and each contributes one catalytic aspartate residue, aspartate $33\left(\mathrm{Asp}_{33}\right)$ and aspartate $219\left(\mathrm{Asp}_{219}\right)$, respectively, thereby forming the active site pocket. The $\mathrm{Y}$ flap region and polyproline loop covered this active site pocket to facilitate substrate binding (Figure 1A). Glycine 79 (Gly 79 ) was situated as a flap tip residue, whereas methionine $297\left(\mathrm{Met}_{297}\right)$ was placed as a hinge residue on the opposite side.

Pepstatin is an inhibitor of both subfamilies of aspartic proteases, A1 and A2 [27]. To explore potential anti-C. sinensis compounds targeting CsCatD2, it is necessary to understand the structure of mature CsCatD2 complexed with pepstatin. Binding of the inhibitor to the active site of CsCatD2 induced conformational changes in the flap region containing conserved Gly79 and the polyproline loop, which recoiled toward the inhibitor. Between CsCatD2 $2_{\text {free }}$ and $\mathrm{CsCatD2}_{\text {bound }}$, the tip-to-tip distance and the hinge-to-hinge distance at $\mathrm{pH} 4.0$ were $4.98 \AA$ and $1.5 \AA$, respectively (Figure 1B). 


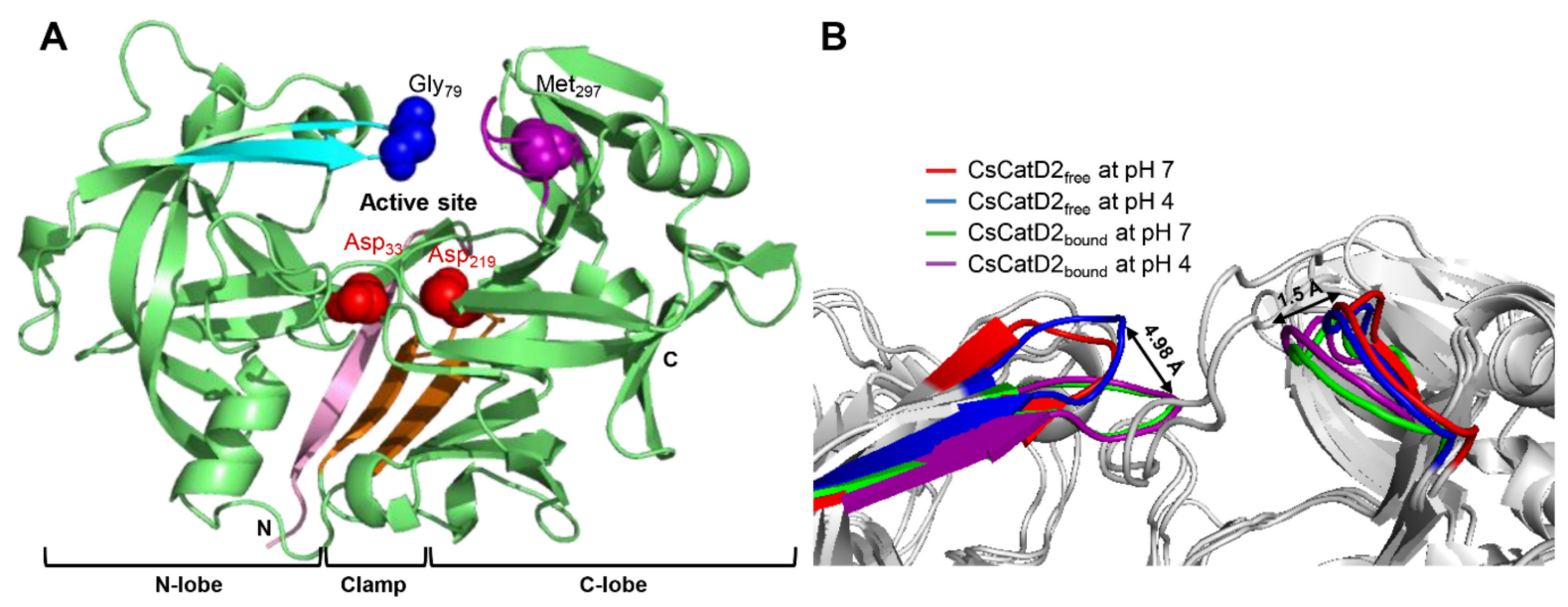

Figure 1. Conserved flap parameters and variations of mature CsCatD2. (A) Y flap region, cyan; polyproline loop, purple; two catalytic aspartic residues, red; flap tip residue, blue; hinge residue of the polyproline loop, purple; N-terminal part, light pink; clamp, orange. (B) Distances of tip-to-tip and hinge-to-hinge between all CsCatD2 models. Flap tip and hinge residues indicate Gly79 and Met $_{297}$, respectively.

\subsection{Four Systems for MD Simulations According to the Enzyme Conformations and $p H$ Values}

The proteolytic activity of CatDs is generally optimum at low $\mathrm{pH}$ and can be detected at neutral $\mathrm{pH}$ for a limited period of time [28]. There have been several reports regarding the optimal $\mathrm{pH}$ for a CatD enzymatic activity which are mentioned as follows: Trichomonas vaginalis CatD proteolytic activity is high at an acidic $\mathrm{pH}(3.5-4.5)$ and low at a $\mathrm{pH}$ close to 7 [29]; optimal pH of HsCatD is in the $\mathrm{pH}$ range 3.0-4.5 [30]. Considering the optimal pH ranges studied previously, we selected acidic $(\mathrm{pH} 4)$ and neutral $(\mathrm{pH} 7)$ conditions to assess the influence of different $\mathrm{pH}$ values on the stability and flexibility of CsCatD2. In addition, it was reported that a 50 nanosecond (ns)-MD simulation is a sufficiently long simulation time to observe all the conformational changes of aspartic peptidases [31,32]. The MD trajectories were analyzed in terms of stability, flexibility, and compactness, including the root mean square deviation (RMSD), root mean square fluctuation (RMSF), radius of gyration $(\mathrm{Rg})$, and solvent-accessible surface area (SASA).

\subsection{CsCatD2 $2_{\text {free }}$ Adopts a Semi-Closed Conformation for Ligand-Binding at Acidic $p H$}

The conformational stability of $\mathrm{CsCatD2}$ free was evaluated by calculating the backbone RMSD by superposing the MD trajectories onto each initial structure at $0 \mathrm{~ns}$. Simulations at the bound states were stable regardless of $\mathrm{pH}$, as evidenced by low and relatively constant RMSD values $(1.48 \pm 0.01, \mathrm{pH} 4$, and $1.53 \pm 0.01, \mathrm{pH} 7)$ of the trajectories (Figure 2A). CsCatD2 free was relatively unstable at $\mathrm{pH} 7$ (average RMSD: $2.36 \pm 0.02$ ) throughout the simulation, which was revealed by the deflection at the beginning of the simulation. However, it remained stable at $\mathrm{pH} 4$ (average RMSD: $1.90 \pm 0.02$ ), comparable to the RMSD level of the bound form until approximately 32.0-35.5 ns. At these specific points-oftime, the RMSD was abruptly increased by $0.8 \AA$ during which a transition in the tertiary structure may have occurred.

To better understand $\mathrm{pH}$-specific conformational change during 30-35 ns, 28 snapshots from each system at 30-36 ns were analyzed using principal component analysis (PCA). Overall, the PCA plot visually indicated that CsCatD2 free was separated from CsCatD2 $2_{\text {bound }}$ along the principal component 1 (PC1), accounting for $88.05 \%$ of the ligandinduced conformational changes while PC2 explains $4.66 \%$ of the $\mathrm{pH}$-dependent variations (Figure 3A and Figure S3). Two snapshots of $\mathrm{pH} 4$ were close to the ones of $\mathrm{pH} 7$ in the CsCatD2 bound and it can contribute to the low score of PC2. However, all snapshots of $\mathrm{pH} 4$ were distinctly far away from the ones of $\mathrm{pH} 7$ for $\mathrm{CsCatD}_{\text {free }}$ and, hence, $\mathrm{PC} 2$ can explain well the large variations of $\mathrm{CsCatD} 2_{\text {free }}$ from $30 \mathrm{~ns}$ to $36 \mathrm{~ns}$. The individual residue contribution to PC2 was examined in more detail by visual inspection (Figure 3B). Clamp 
hairpin (aa 158-168) between $\beta$-strand $7\left(\beta_{7}\right)$ and $\beta_{8}$ showed the highest contribution to the PC2. N-terminal end, two hairpins including aa 284-287 between $\beta_{14}$ and $\beta_{15}$, and aa 266-269 region between $\beta_{12}$ and $\beta_{13}$ also contributed significantly to the PC2. Remarkably, $\mathrm{N}$-terminal end tended to shift to open the active site and also the distance between the flap tip and hinge residue was gradually decreased in $\mathrm{CsCatD}_{\text {free }}$ at $\mathrm{pH} 4$ at different time-points 32.0, 33.50, and 34.25 ns (Figure S4). The RMSD was then maintained at a steady level upon adopting a new conformation, as supported by the increasing number of hydrogen bonds in $\mathrm{CsCatD}_{\text {free }}$ at $\mathrm{pH} 4$ (Figure 2A and Figure S5). Secondary structure elements showed considerable conformational change according to the $\mathrm{pH}$ effect and simulation time. In particular, $\beta_{11}$ including $A_{s p_{219}}, \beta_{12}$, and $\beta_{13}$ formed only at $\mathrm{pH} 4$. These results suggest that acidification of 30-36-ns simulation can contribute to major conformational changes in $\mathrm{CsCatD2} 2_{\text {free }}$ from open to closed/semi-closed conformations.
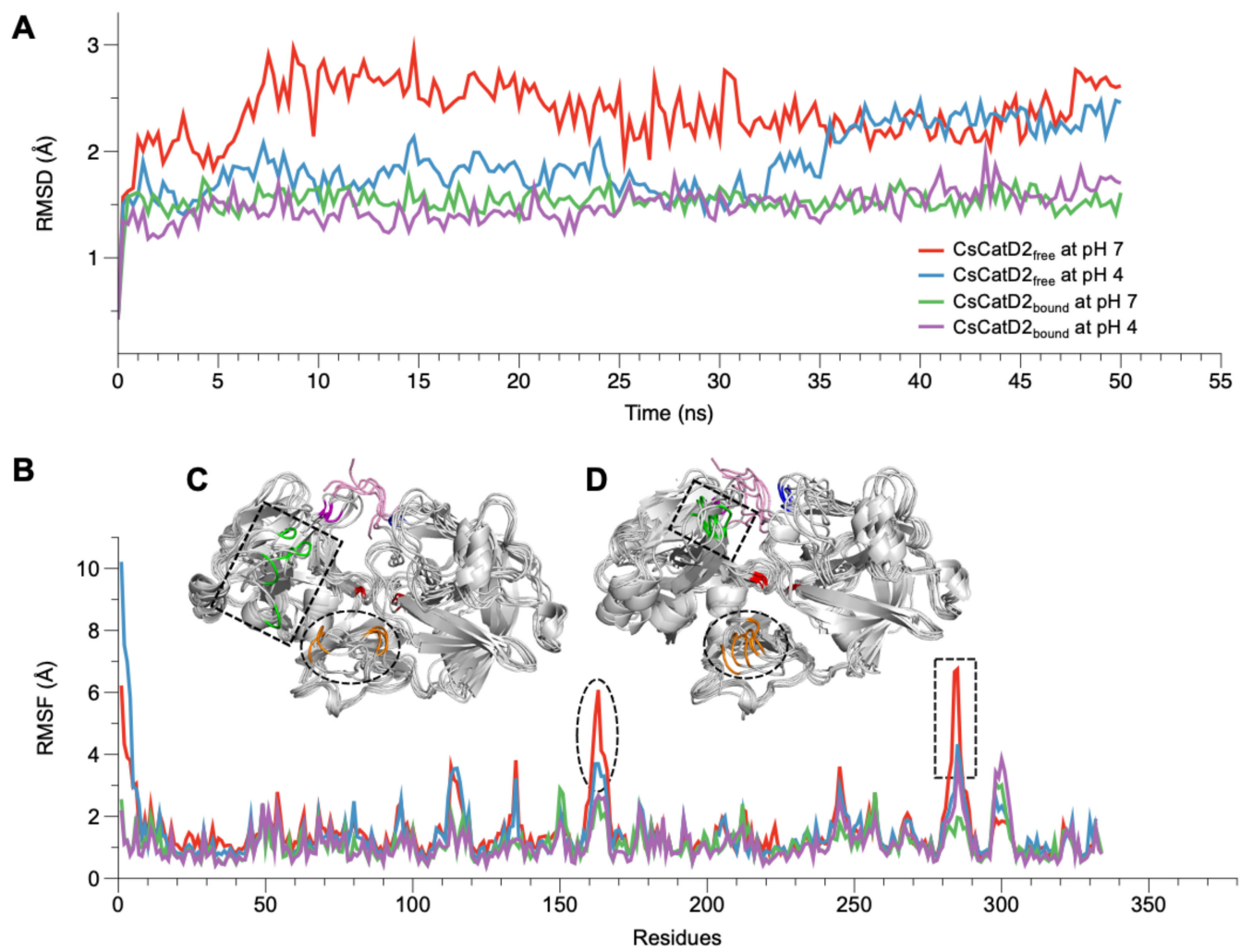

Figure 2. RMSD and RMSF variations of $\mathrm{CsCatD} 2_{\text {free }}$ and $\mathrm{CsCatD2}{ }_{\text {bound }}$ models at both $\mathrm{pH}$ conditions. During the 50-ns MD simulation at neutral $(\mathrm{pH} 7)$ and acidic $(\mathrm{pH} 4)$ condition, fluctuations of RMSD (A) and RMSF (B) are shown based on the time and residues, respectively. (C,D) Structural variations of $\mathrm{CsCatD}_{\text {free }}$ at $\mathrm{pH} 7$ (C) and $\mathrm{pH} 4$ (D) values during the MD simulation. Backbone snapshots of both proteins are in shades of gray, each of which were obtained at $0,10,20,30,40$ and $50 \mathrm{~ns}$. The back view is rotated by $180^{\circ}$ about a vertical axis, relative to the view shown in Figure $4 \mathrm{~A}$. The dotted circle and rectangle correspond with each region having high RMSF value, such as aa 162-163 (orange part) and aa 284-285 (green part). The remaining color legend is provided in the legend to Figure $4 \mathrm{~A}$.

\subsection{Both Ligand-Binding and Acidic $p H$ Limit the Conformational Flexibility}

RMSF provides insights regarding the flexible or disordered regions of molecules in a biological system during MD simulations [33]. In this study, residual atomic fluctuations in all systems showed similar trends below $4 \AA$ throughout the course of the simulations, except for $\mathrm{CsCatD}_{\text {free }}$ at $\mathrm{pH} 7$ (Figure 2B). Overall, the free forms at $\mathrm{pH} 7$ (average RMSF: 1.53) and $\mathrm{pH} 4$ (average RMSF: 1.44) showed higher flexibility than bound forms at both pH values (average RMSF: 1.11). Two regions (aa 162-163 and aa 284-285) exhibited larger 
deviations of up to $7 \AA$ from its starting structure in $\mathrm{CsCatD2} 2_{\text {free }}$ at $\mathrm{pH} 7$ than at $\mathrm{pH} 4$ (Figure $2 \mathrm{C}, \mathrm{D}$ ). ${ }_{162} \mathrm{DV}_{163}$ lies in the hairpin of the clamp region between the $\mathrm{N}$ - and Ctermini, whereas ${ }_{284} \mathrm{YR}_{285}$ belongs to the $\beta$-loop region and is located near the polyproline loop. The results are in broad accordance with PCA analysis of 30-36-ns simulation, which exhibits high residual contributions of the clamp's hairpin and $\beta$-loop region. This is also consistent with a previous report that flexibility occurs in some regions of free HsCatD owing to the absence of ligands [32]. Thus, it may be suggested that $\mathrm{pH}$ itself can affect major conformational fluctuations in $\mathrm{CsCatD2}_{\text {free }}$ as shown by the increase in $\mathrm{pH}$ toward neutral conditions, which caused great fluctuations in the two regions in CsCatD2 $2_{\text {free. }}$.
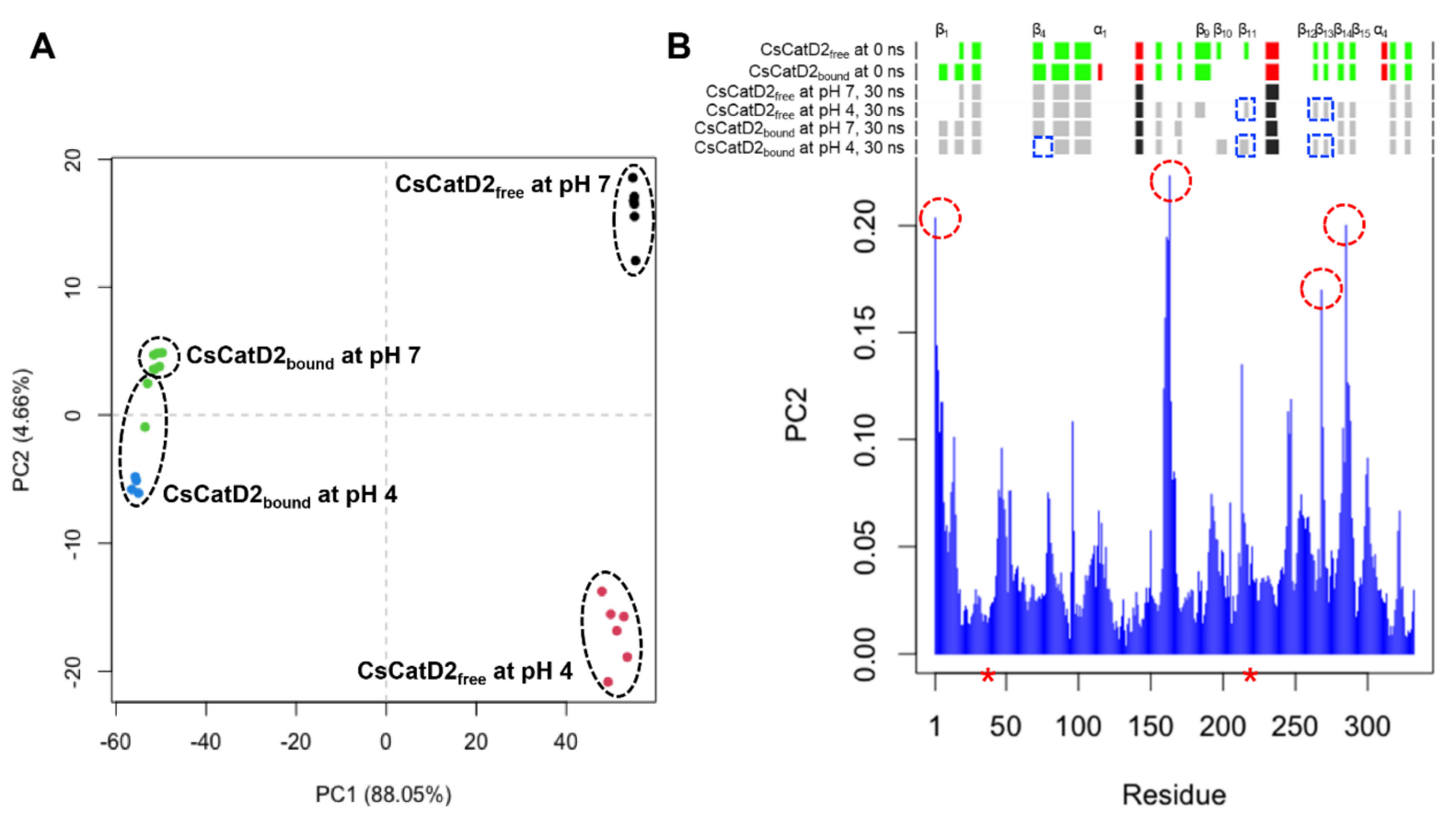

Figure 3. Principal component analysis (PCA) analysis of 28 snapshots during 30-36 ns MD simulation. (A) Projection of the motion of $\mathrm{CsCatD2}_{\text {free }}$ and $\mathrm{CsCatD2}{ }_{\text {bound }}$ at neutral $(\mathrm{pH} 7)$ and acidic $(\mathrm{pH} 4)$ condition in phase space along the eigenvectors 1 (PC1) and 2 (PC2). Color labels were assigned to each snapshot, depending on its assigned cluster. (B) Contribution of each residue of CsCatD2 to the PC2. Residues showing high contribution are marked by a red circle. Secondary structure elements were predicted using DSSP (https:/ / swift.cmbi.umcn.nl/gv/dssp/; accessed on 10 August 2021) and $\mathrm{pH}$-dependent alterations are marked by a blue rectangle. Colors and alphabets identify $\alpha$-helices (red and black) and $\beta$-strands (green and gray). Asterisk symbols indicate the two catalytic aspartic residues, Asp 33 and Asp219.

\subsection{Neutral pH May Induce the Opening of Potential Allosteric Inhibitory Sites}

Based on the average B-factor models for all systems, the N-terminal part covered the entrance of the active site in $\mathrm{CsCatD2} 2_{\text {free }}$ (Figure $4 \mathrm{~A}, \mathrm{~B}$ ), whereas there was no steric hindrance involving the entrance in the $\mathrm{CsCatD2}{ }_{\text {bound }}$ (Figure $4 \mathrm{C}, \mathrm{D}$ ). In the free forms, three flexible regions ( $\mathrm{N}$-terminus, aa 162-163, and aa 284-285) were detected and the latter two regions showed higher mobility at $\mathrm{pH} 7$ than at $\mathrm{pH} 4$ in the bound forms as shown by the RMSF values (Figure 4A,B). For CsCatD2 $2_{\text {free, }}$ as described above, no hydrogen bond formation of the flap tip Gly79 (average RMSF: 1.55) with the inhibitor can have a critical impact on the overall flexibility and polyproline loop as compared to the CsCatD2 ${ }_{\text {bound }}$ (average RMSF: 0.66, Gly79) under both $\mathrm{pH}$ conditions. These findings are consistent with the fact that the flexible loop folds inward over the active site and interacts with the flap as the HsCatD closes [32,34].

Remarkably, the region flanking aa 149-152 exhibited high flexibility only in CsCatD2 ${ }_{\text {bound }}$ at $\mathrm{pH} 7$ (Figure 4C). This highly mobile region was located at the boundary of the potential allosteric pocket, all of which were matched between CsCatD2 (glycine $14\left(\mathrm{Gln}_{14}\right)$, tyrosine $15\left(\mathrm{Tyr}_{15}\right)$, tyrosine $16\left(\mathrm{Tyr}_{16}\right)$, phenylalanine $32\left(\mathrm{Phe}_{32}\right)$, alanine 97 
(Ala97), valine $149\left(\mathrm{Val}_{149}\right)$, glutamine $\left(\mathrm{Glu}_{170}\right)$, isoleucine 171 (Ile 171$)$, and phenylalanine $\left.173\left(\mathrm{Phe}_{173}\right)\right)$ and IrCatD1 (valine $39\left(\mathrm{Val}_{39}\right)$, tyrosine $40\left(\mathrm{Tyr}_{40}\right)$, tyrosine $41\left(\mathrm{Tyr}_{41}\right)$, phenylalanine 57 (Phe 57$)$, alanine 120 ( $\left.\mathrm{Ala}_{120}\right)$, leucine $172\left(\mathrm{Leu}_{172}\right)$, glutamine $193\left(\mathrm{Glu}_{193}\right)$, valine $194\left(\mathrm{Val}_{194}\right)$, and phenylalanine 196 (Phe $\left.{ }_{196}\right)$ ) with a template modeling (TM) score of 93\% (Figure S6). These findings together with recent reports indicating that the allosteric mechanism regulates pepsin-family peptidases $[28,35]$ suggest that neutral $\mathrm{pH}$ can induce the opening of the allosteric site of CsCatD2 similar to HsCatD and IrCatD [28,36]. Recently, propeptide-derived inhibitor allosterically inhibits IrCatD activity [28]. The allosteric mechanism for the peptidyl inhibitor is strikingly different as the potency of the allosteric inhibitor is $\mathrm{pH}$-dependent. A pH shift toward neutral condition displaces the $\mathrm{N}$-terminus of mature CatDs into the active site and opens the allosteric site. Thus, an inhibitor (pepstatin) may preferentially bind to the active site of CatDs at an acidic $\mathrm{pH}$, whereas allosteric inhibitor (peptidyl inhibitor) favorably binds to an allosteric inhibitory site.

A

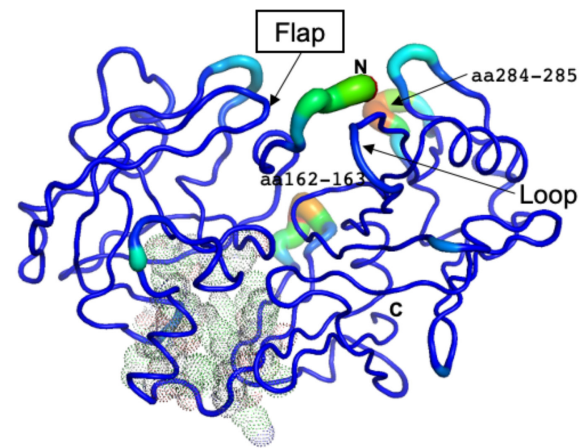

C

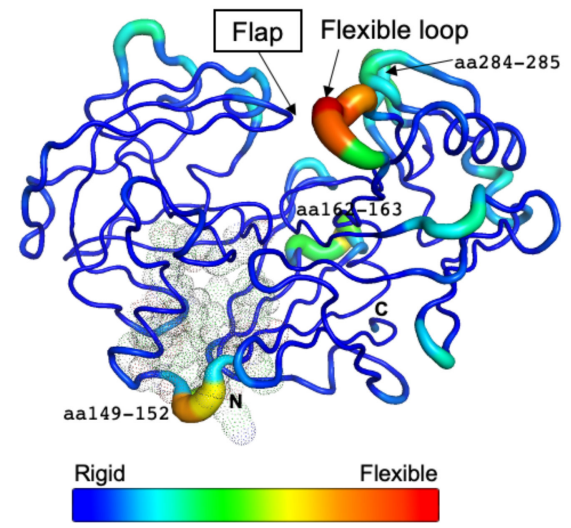

B

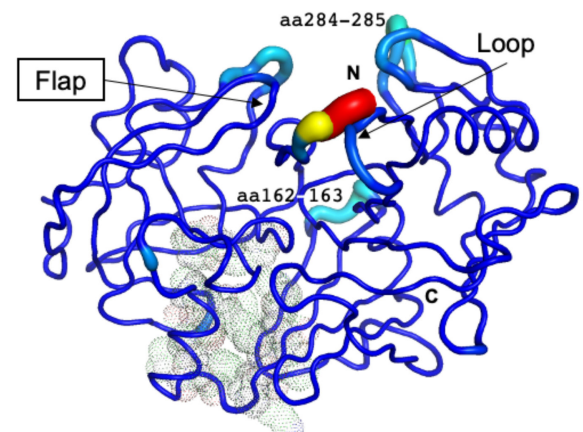

D

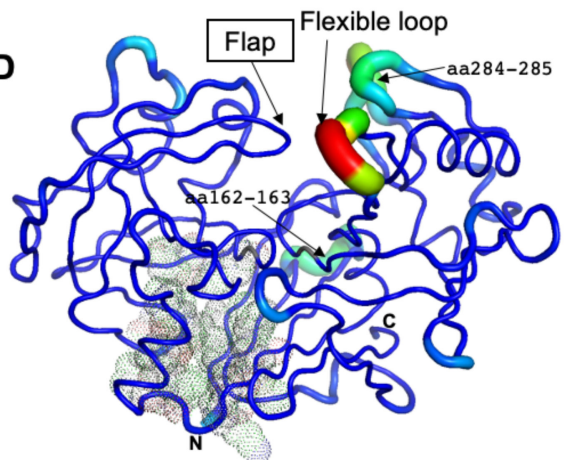

Figure 4. Residual flexibility of the free and bound forms at different $\mathrm{pH}$ conditions. The average B-factor-derived mobilities of $\mathrm{CsCatD2} 2_{\text {free }}$ at pH 7 (A) and at pH 4 (B), CsCatD2 $2_{\text {bound }}$ at $\mathrm{pH} 7$ (C) and $\mathrm{pH} 4$ (D) were visualized. All residues (at positions 14-16, 32, 97, 149, 170, 171, and 173) of potential allosteric inhibitory sites are indicated with black dots (see Section 2.5).

\subsection{Acidic $p H$ Enhances the Compactness of CsCatD2 free to Converge to the Level of Bound Forms}

To monitor the compactness of $\mathrm{CsCatD2} 2_{\text {free }}$ and $\mathrm{CsCatD2} 2_{\text {bound }}$ structures, $\mathrm{Rg}$ and SASA were analyzed as the indicators of protein structure compactness in all systems. $\mathrm{Rg}$ indicates the mass-weighted RMSD between the common center-of-mass and a collection of atoms [37]. Although the low Rg values of CsCatD2 ${ }_{\text {bound }}$ were consistent regardless of $\mathrm{pH}$, the $\mathrm{Rg}$ values of $\mathrm{CsCatD2}$ free tended to decline (Figure $5 \mathrm{~A}$ ). Remarkably, the $\mathrm{Rg}$ value of $\mathrm{CsCatD2}_{\text {free }}$ at $\mathrm{pH} 4$ approached close to the level of $\mathrm{CsCatD2}_{\text {bound }}$ and eventually converged at approximately $44 \mathrm{~ns}$. These results were further supported by the SASA value, which measures the exposed surface of the entire enzyme that is accessible to solvent molecules [38]. The overall trend of the SASA corresponded to fluctuations in the Rg values for all systems. At approximately $44 \mathrm{~ns}$, the convergence of the SASA in CsCatD2 free at $\mathrm{pH} 4$ occurred at the level of $\mathrm{CsCatD2}{ }_{\text {bound }}$ (Figure 5B). These processes were in line with 
the abrupt changes in the RMSD values. The low $\mathrm{Rg}$ and SASA values throughout the remainder of the simulations were also consistent with the adoption of a new conformation.

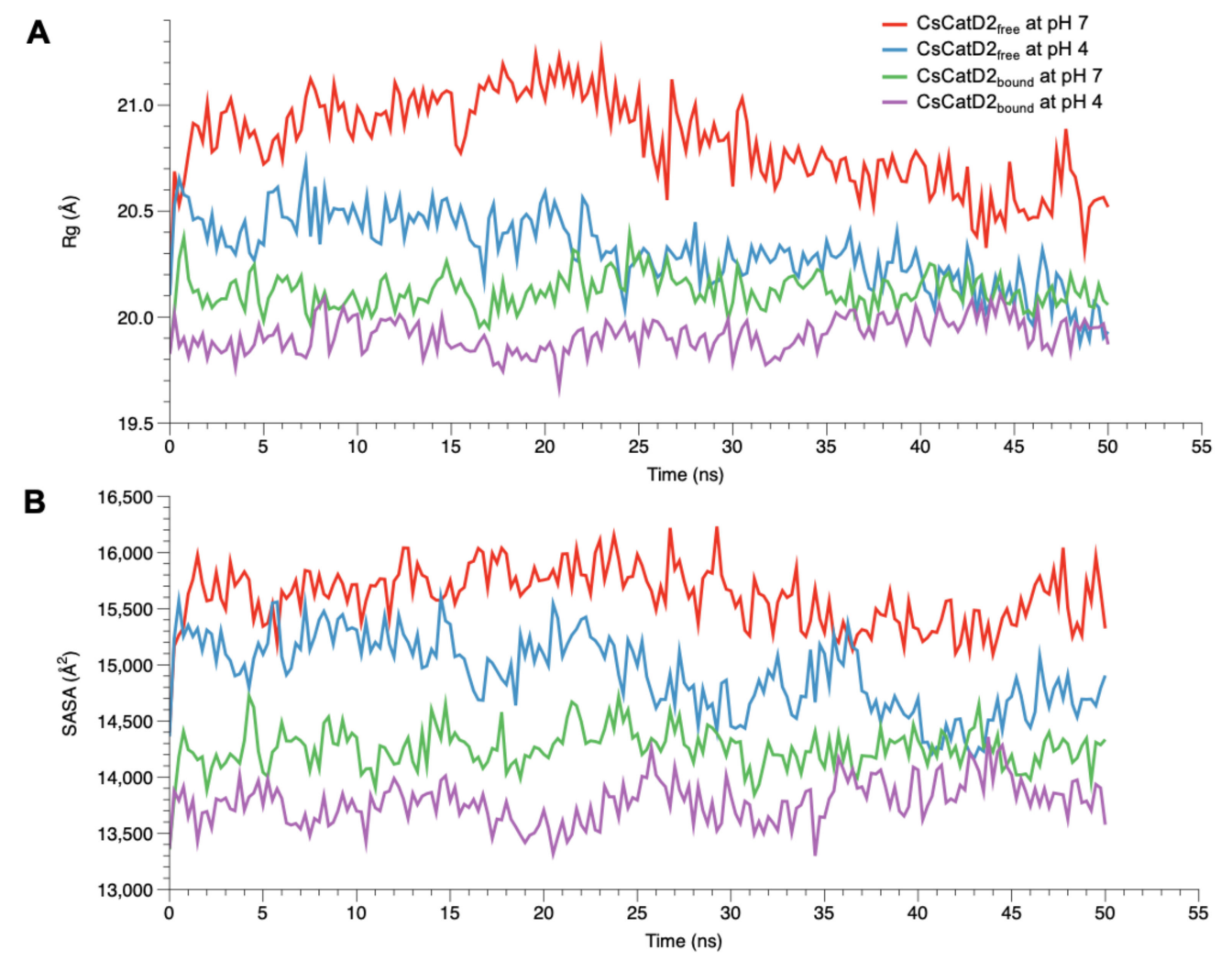

Figure 5. Conformational changes of free and bound CsCatD2 at both $\mathrm{pH}$ conditions. $\mathrm{Rg}(\mathbf{A})$ and SASA (B) of CsCatD2 $2_{\text {free }}$ and CsCatD2 ${ }_{\text {bound }}$ were calculated at neutral $(\mathrm{pH} 7)$ and acidic $(\mathrm{pH} 4)$ condition throughout the trajectory of $50 \mathrm{~ns}$.

\subsection{Acidic pH Alters Correlated Motions and Hydrogen Bonds Occupancy}

Dynamic cross-correlation map (DCCM) is one of the most effective methods for understanding two-dimensional dynamic information of all the $\mathrm{C} \alpha$ atom fluctuations of proteins [ref]. The effect of either acidic $\mathrm{pH}$ or inhibitor-binding, and both effects on the correlated motions of CsCatD2 $2_{\text {free }}$ were investigated (Figure 6). Overall, highly positive correlation regions were observed along the $\mathrm{N}$ - and $\mathrm{C}$-lobes and clamp regions. It could be clearly seen that compared with the $\mathrm{CsCatD} 2_{\text {free }}$ at $\mathrm{pH} 7$ (Figure 6A), the correlated motions were substantially increased in the $\mathrm{CsCatD}_{\text {bound }}$ at $\mathrm{pH} 4$ (Figure 6D) but slightly increased in the $\mathrm{CsCatD2}$ free $_{\text {at }} \mathrm{pH} 4$ (Figure 6B) and $\mathrm{CsCatD2}$ bound at $\mathrm{pH} 7$ (Figure 6C). Interestingly, acidic $\mathrm{pH}$ alone can contribute on the dynamic correlation and, thus, correlated motions of $\mathrm{CsCatD} 2_{\text {free }}$ at $\mathrm{pH} 4$ had similar ones of $\mathrm{CsCatD2}{ }_{\text {bound }}$ at $\mathrm{pH}$ 7. The results were consistent with the RMSD and $\mathrm{Rg}$ results. Our finding indicates that both acidic $\mathrm{pH}$ and inhibitorbinding could be prerequisite factors for its enzymatic reaction. For the catalytic reaction, the active site pocket needs to be closed which means that movements of the N-lobe and C-lobe should be oriented toward each other, around the pocket.

To explore how CsCatD2 ${ }_{\text {bound }}$ interacts with the inhibitor under different $\mathrm{pH}$ conditions, hydrogen bond and hydrophobic interactions were investigated because hydrogen bonds between inhibitor and surrounding residues are crucial for stabilizing the complex. Noncovalent interactions changed with time during the 50-ns simulation. In particular, acidic $\mathrm{pH}$ significantly contributed high hydrogen bond occupancy of the whole simulation time at the $\mathrm{Asp}_{33}$ of 94 to $99 \%$ and $\mathrm{Asp}_{219}$ of 0 to $91 \%$ (Figure $7 \mathrm{~A}$ ). CsCatD2 ${ }_{\text {bound }}$ at pH 4 appeared to adopt a more closed conformation than that at $\mathrm{pH} 7$ due to higher hydrogen bond occupancy at the Asp 219, Met $_{297}$ and Ile 306 (Figure 7B). 

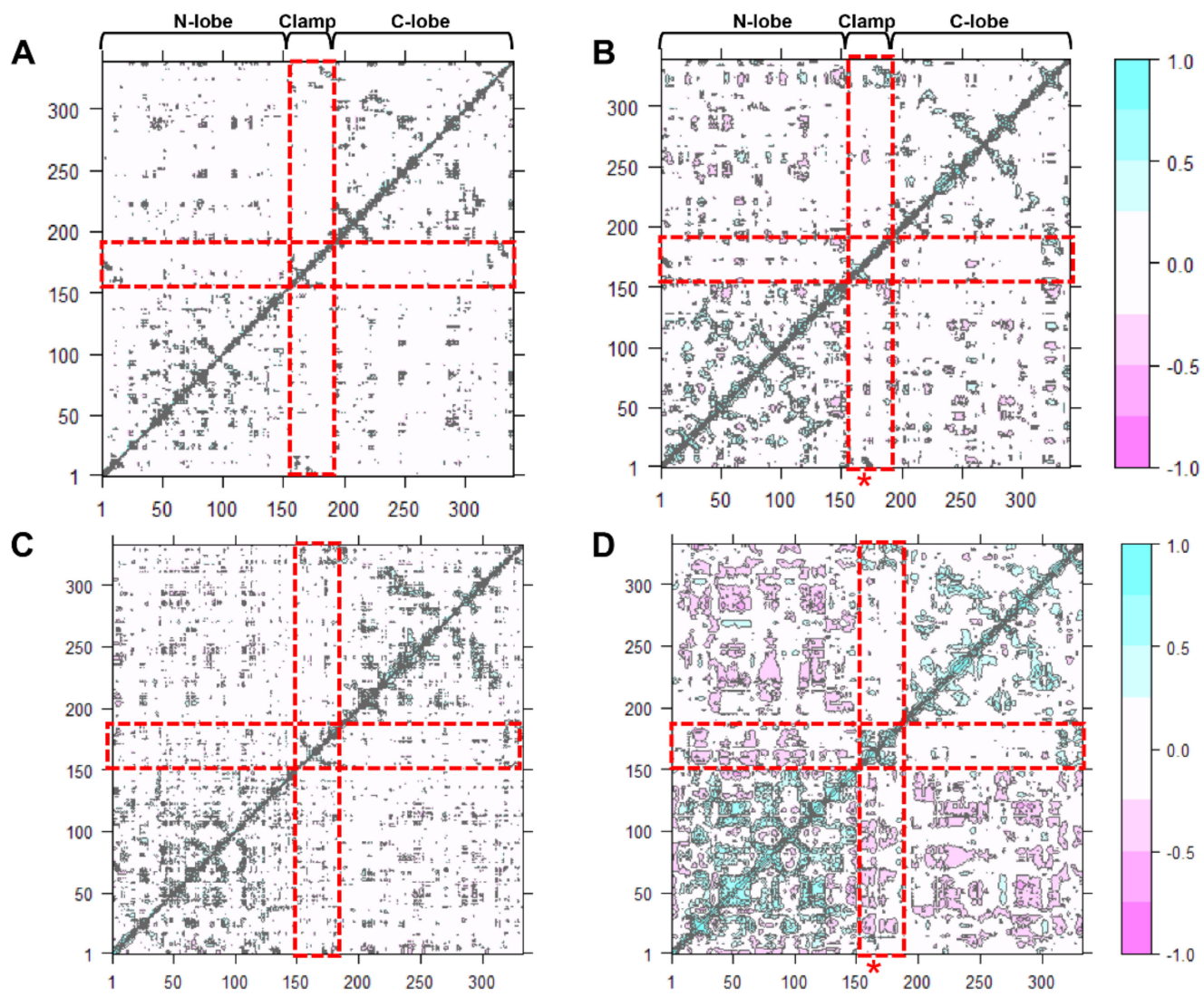

Figure 6. Dynamic cross-correlation map of the $\mathrm{C} \alpha$ atoms of $\mathrm{CsCatD2}$ during 50-ns MD simulation. CsCatD2 ${ }_{\text {free }}$ at $\mathrm{pH} 7$ (A) and at pH 4 (B), CsCatD2 bound at $\mathrm{pH} 7$ (C) and pH 4 (D). The cyan color indicates positive correlated motions, and the pink color shows negative correlated motions. Red rectangles depict N-lobe (aa 1-152), clamp (aa 153-172) and C-lobe (aa 173-332). Asterisk symbols indicate the two catalytic aspartic residues, $\mathrm{Asp}_{33}$ and $\mathrm{Asp}_{219}$.

\subsection{Twisting of the Active Site Pocket by the Bound Inhibitor and Acidic $\mathrm{pH}$}

Flap dynamics imply the time-dependent changes in the physical interactions and conformational flexibilities of the flap region and loops. Based on the structural dynamics, it indicates time-dependent conformational changes in proteins [24,25]. Specific structural metrics have been previously suggested for the flap dynamics of CatD [25]. The distance $d_{1}\left(\mathrm{Gly}_{79}-\mathrm{Met}_{297}\right)$ between the flap tip and hinge residue, TriC $\alpha$ angles, $\theta_{1}$ (Gly ${ }_{79}-\mathrm{Asp}_{33^{-}}$ Met $\left._{297}\right)$ and $\theta_{2}$ (Gly ${ }_{79}-$ Asp $_{219}-$ Met $_{297}$ ), which account for the opening and closing of the active site, and dihedral angle $\phi\left(\mathrm{Gly}_{79}-\mathrm{Asp}_{33}-\mathrm{Asp}_{219}-\mathrm{Met}_{297}\right)$ are responsible for the twisting motion (Figure 8A).

The dynamics of the flap structure of CsCatD2 were analyzed. Based on the average structures obtained through a 50-ns MD simulation, each parameter was measured (Figure 8B). The conformational states of CsCatD2 were determined according to the distance $d_{1}$ as suggested by Kumalo and Soliman [39]. It was found that the open state was higher than $13 \AA$, the closed state was lower than $9 \AA$, and either the semi-open or semi-closed state existed between the two values. In addition to ligand-binding, acidic $\mathrm{pH}$ decreased the distance $d_{1}$ as follows: from open (13.8 $\left.\mathrm{A}\right)$ to semi-open $(12.6 \AA)$ state in CsCatD2 $2_{\text {free; }}$ and from semi-closed $(9.7 \AA)$ to closed $(8.7 \AA)$ state in CsCatD2 ${ }_{\text {bound }}$. Compared to the initial structures, the acidic $\mathrm{pH}$ and bound inhibitor steered the dihedral angle $\phi$ and reduced the TriC $\alpha$ angles $\left(\theta_{1}\right.$ and $\left.\theta_{2}\right)$ simultaneously. Both the distance $d_{1}$ and TriC $\alpha$ angles are likely to decrease. For instance, the dihedral angle $\phi$ of $\mathrm{CsCatD2} 2_{\text {free }}$ at $\mathrm{pH} 7$ shifted from $+2.1^{\circ}$ to $-4.7^{\circ}$ at acidic $\mathrm{pH}$, to $-8.0^{\circ}$ for the bound ligand, and to $-3.8^{\circ}$ for both factors. These results collectively provide evidence of the "twisting" of the binding 
pocket, which can be seen by the asymmetrical movement of the pocket by the bound inhibitor and acidic $\mathrm{pH}$.

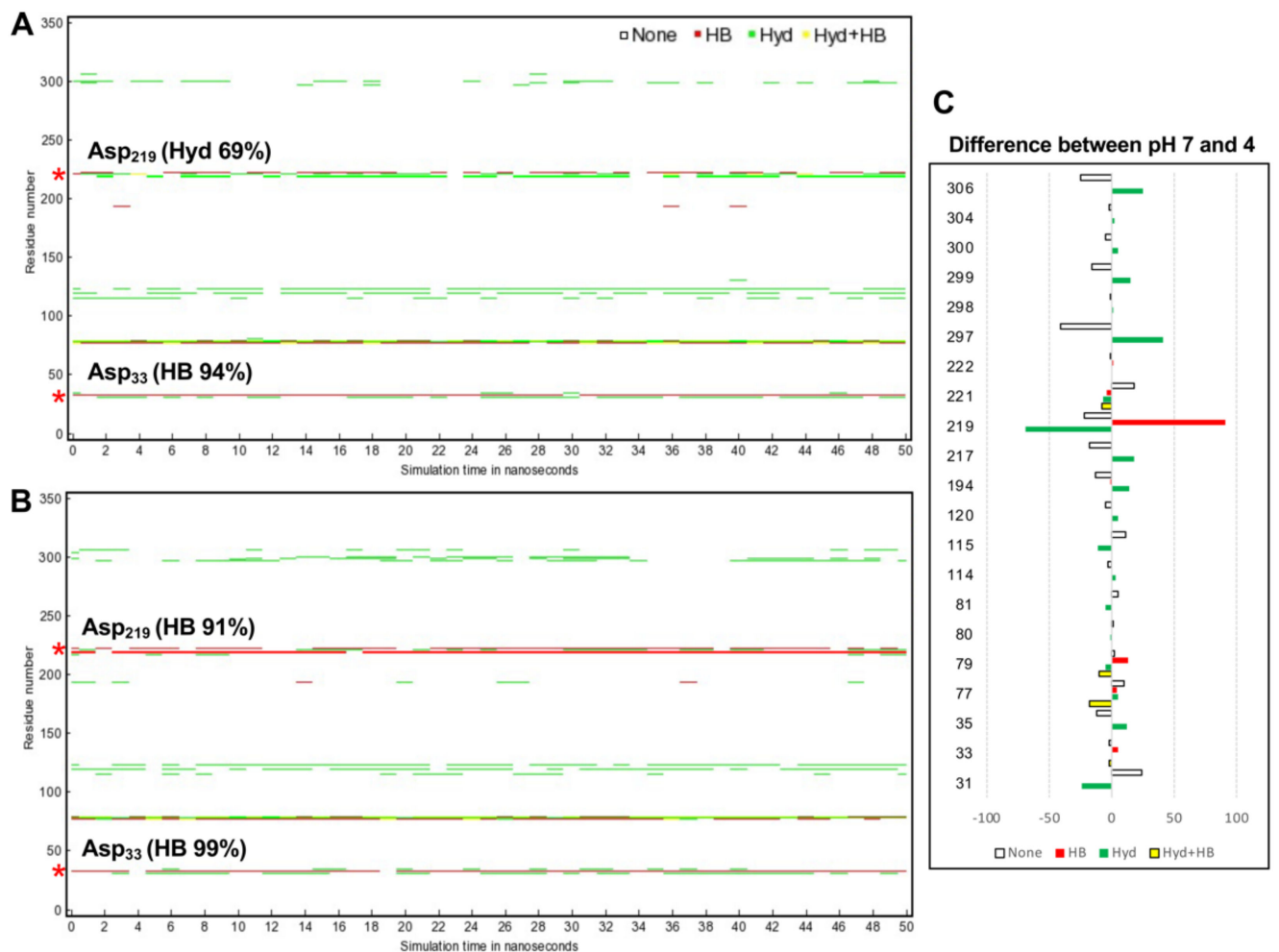

Figure 7. Protein-inhibitor contact plot with per-residue interactions of CsCatD2 ${ }_{\text {bound }}$ at $\mathrm{pH} 7$ (A) and $\mathrm{pH} 4$ (B) during 50-ns MD simulation. (C) Residue list shows fluctuations of per-residue contacts by subtraction of the value for $\mathrm{CsCatD} 2_{\text {bound }}$ at $\mathrm{pH} 4$ (right) from the corresponding value at $\mathrm{pH} 7$ (left). HB, hydrogen bonds in red; Hyd, hydrophobic contacts in green; Hyd+HB, both hydrogen bonds and hydrophobic contacts in yellow. Asterisk symbols indicate the two catalytic aspartic residues, $\mathrm{Asp}_{33}$ and $\mathrm{Asp}_{219}$.

\subsection{Effect of Acidic $p H$ on Flap Dynamics and Its Correlation with the Twisting Motion of the} Active Site Pocket

The time-series distance $d_{1}$ was calculated based on the snapshots obtained at 0,10 , 20, 30, 40, and 50 ns during the 50-ns MD trajectories of all systems (Figure 9). The mean and standard error of the distance $d_{1}$ were calculated for $\mathrm{CsCatD2}_{\text {free }}$ at $\mathrm{pH} 7(14.85 \pm 0.54)$, $\mathrm{CsCatD}_{\text {free }}$ at $\mathrm{pH} 4(12.66 \pm 0.10), \mathrm{CsCatD}_{\text {bound }}$ at $\mathrm{pH} 7(10.52 \pm 0.46)$, and CsCatD2 $2_{\text {bound }}$ at $\mathrm{pH} 4(8.69 \pm 0.04)$ (Tables S1 and S2). At the beginning of the simulation, the distance $d_{1}$ showed semi-open conformation (11.30 $\AA$ at $\mathrm{pH} 7$ and $11.29 \AA$ at $\left.\mathrm{pH} 4\right)$ in $\mathrm{CsCatD2} 2_{\text {free }}$ whereas $d_{1}$ indicated a semi-closed conformation $(9.20 \AA$ at $\mathrm{pH} 7$ and $9.66 \AA$ at $\mathrm{pH} 4)$ in CsCatD2 $2_{\text {bound }}$. Toward the end of the 50-ns MD simulation, CsCatD2 $2_{\text {free }}$ showed only two open states at $\mathrm{pH} 4$ and then transitioned to a semi-closed state $(10.60 \AA)$ at 50 ns. Although the bound forms showed a similar trend at both $\mathrm{pH}$ conditions, CsCatD2 bound $_{\text {on }}$ had a lower minimum $d_{1}$ of $7.74 \AA$ at $\mathrm{pH} 4$ than the $d_{1}(8.74 \AA$ ) at $\mathrm{pH} 7$ at 50 ns, revealing three semi-closed conformations or three closed states. Notably, the acidic $\mathrm{pH}$ induced the distance $d_{1}$ of CsCatD2 $2_{\text {free }}$ close to the level of CsCatD2 ${ }_{\text {bound }}$ at $\mathrm{pH} 7$ around the simulation times (5, 21, 34, and $46 \mathrm{~ns})$ (Figure 10A, Tables S1 and S2). 
A

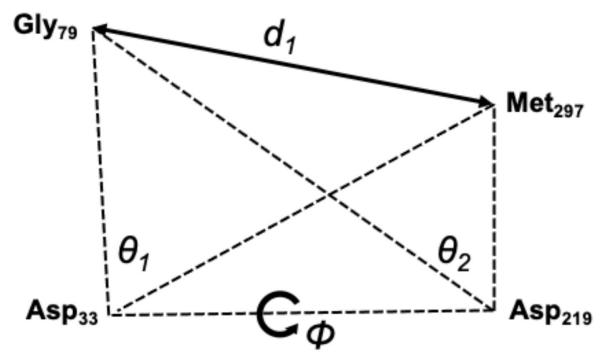

B

pH 7

pH 4

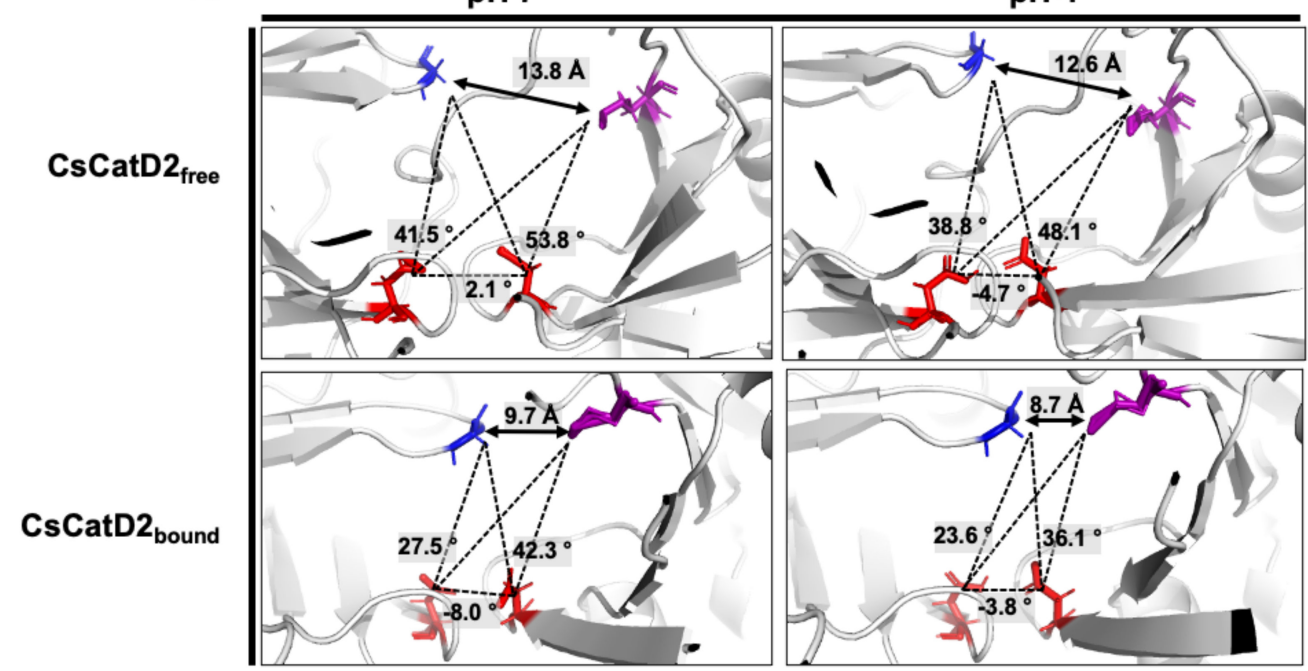

Figure 8. Schematic representation to define the flap-structure dynamics in the free and bound CsCatD2. (A) Parameters used to describe the flap dynamics of the active site and flap region: the distance $\left(d_{1}\right)$ between the flap tip and flexible region hinge residue, the dihedral angle $(\phi)$ and the TriC $\alpha$ angles $\left(\theta_{1}\right.$ and $\left.\theta_{2}\right)$. (B) Parameter values obtained from the average free and bound CsCatD2 during MD simulations at neutral $(\mathrm{pH} 7)$ and acidic $(\mathrm{pH} 4)$ conditions. Four residues in active sites are shown in sticks.

A similar trend was also observed at the dihedral angle $\phi$ in $\mathrm{CsCatD2} 2_{\text {free }}$ at $\mathrm{pH} 4$ (Figure 10B). CsCatD2 free at $\mathrm{pH} 7$ (average $\phi: 2.29 \pm 0.43$ ) showed a few small negative values of $\phi$ on an intermittent basis, whereas $\mathrm{CsCatD}_{\text {free }}$ at $\mathrm{pH} 4$ (average $\phi:-4.68 \pm 0.43$ ) made the preferable twisted conformation as represented by a majority of negative values of $\phi$. Acidic $\mathrm{pH}$ induced opposite patterns of $\phi$ in CsCatD2 ${ }_{\text {free }}$ during 40-50 ns via conformational shifts to the semi-open state (ranging from 16.24 to 5.59 ) at $\mathrm{pH} 7$ and semi-closed state (from -18.36 to -6.54 ) at $\mathrm{pH} 4$. The bound forms had negative values of dihedral angles $\phi,-7.56 \pm 0.38$ at $\mathrm{pH} 7$ and $-3.78 \pm 0.19$ at $\mathrm{pH} 4$, throughout the entire simulation time. Among the TriC $\alpha$ angles $\theta_{1}$ and $\theta_{2}$ (Figure 10C,D), the angle $\theta_{1}$ was more consistent with the distance $d_{1}$, suggesting that these factors may work together to ensure the timely conformational changes of CsCatD2. Therefore, the three parameters $\left(d_{1}, \phi\right.$, and $\left.\theta_{1}\right)$ of flap dynamics were correlated with each other to account for the discrepancies in the open or closed states of the binding cleft. 


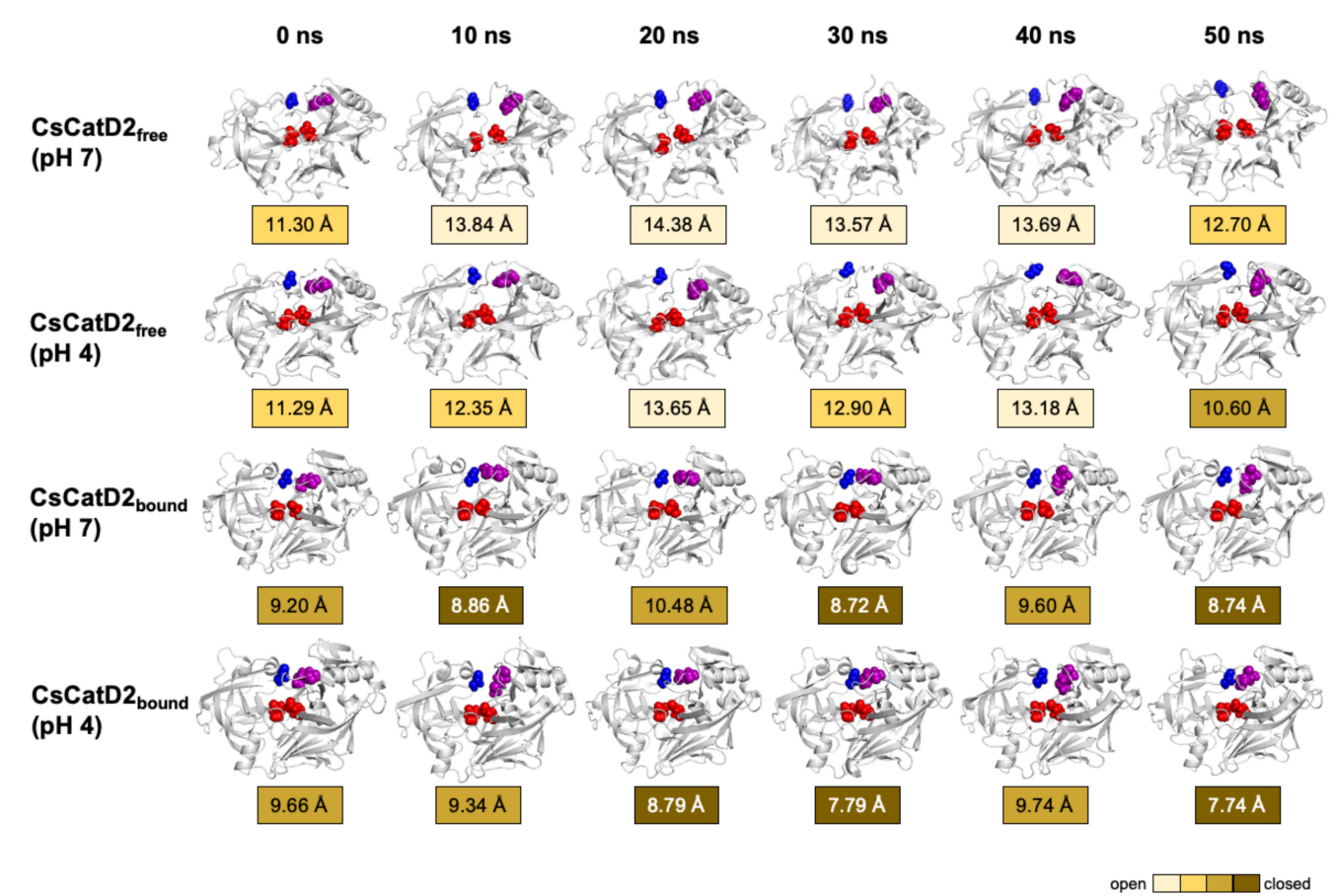

Figure 9. Time-series snapshots of $d_{1}$, the distance between the flap tip and hinge residue, throughout the 50-ns MD simulation. Structural changes of the distance $d_{1}$ of CsCatD2 $2_{\text {free }}$ and CsCatD2 $2_{\text {bound }}$ were visualized based on the six time points $0,10,20,30,40$ and $50 \mathrm{~ns}$. The conformational states were determined according to the distance $d_{1}$ as suggested by Kumalo and Soliman [39], such as open state of $d_{1}>13 \AA$, closed state of $d_{1}<9 \AA$ and semi-conformational state of $9 \leq d_{1} \leq 13$. Four residues in active sites are shown by spheres in the same color as in Figure 1A.
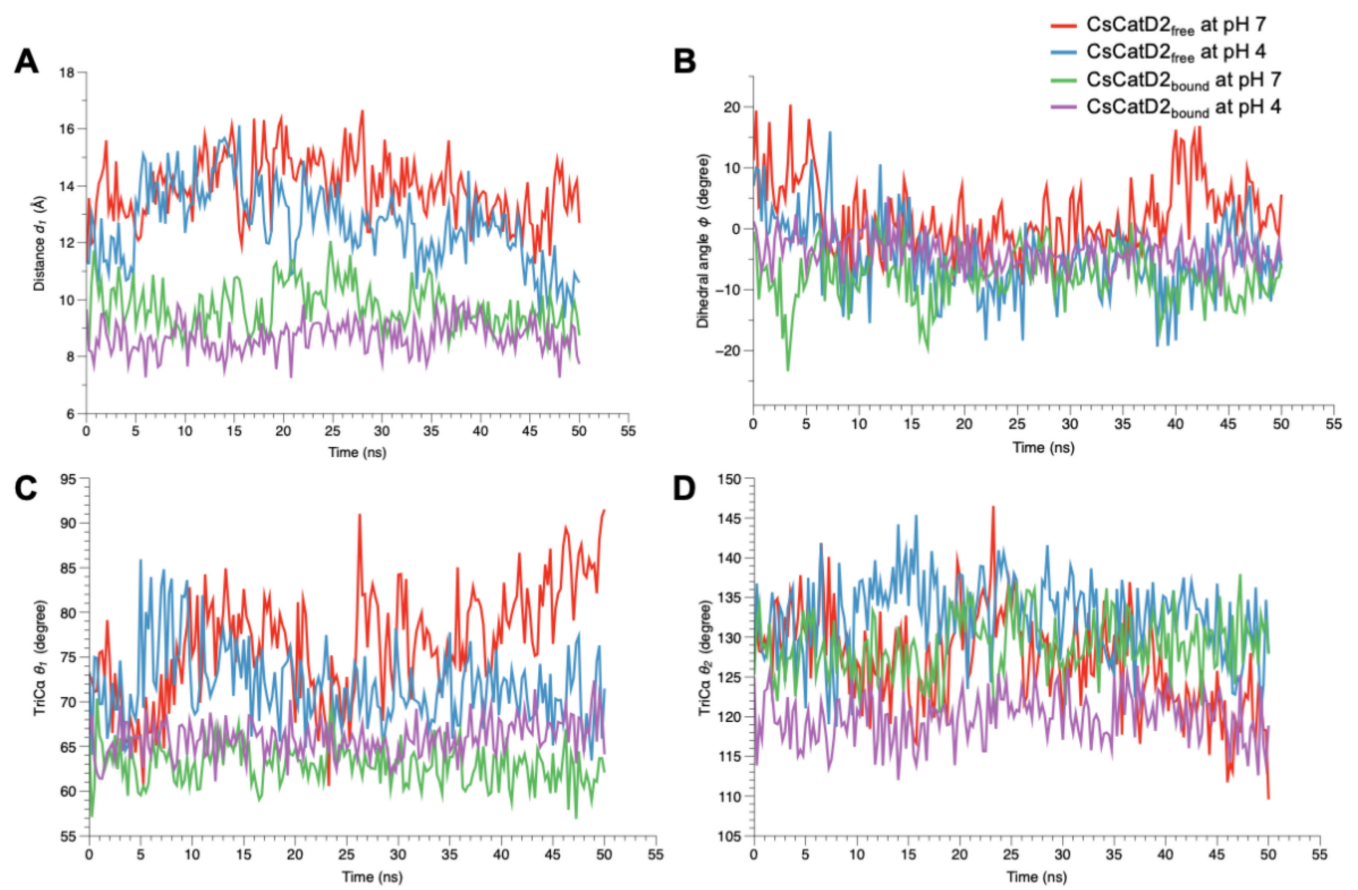

Figure 10. Flap dynamics of free and bound CsCatD2 throughout the trajectory of 50 ns. Flap parameters of $\mathrm{CsCatD} 2_{\text {free }}$ and $\mathrm{CsCatD} 2_{\text {bound }}$ were determined according to both $\mathrm{pH}$ conditions, pH 7 and pH 4. (A) distance $d_{1},(\mathbf{B})$ dihedral angle $\phi,(\mathbf{C})$ TriC $\alpha$ angle $\theta_{1}$ and (D) TriC $\alpha$ angle $\theta_{2}$. 


\section{Materials and Methods}

\subsection{Homology Modeling and Verification}

The complete mRNA sequence of CsCatD2 was retrieved from GenBank (Acc. No.: GU433605) [23] and the amino acid sequence was deduced using the Lasergene software (DNASTAR, Madison, Wisconsin, USA). The 3D homology models of CsCatD2 ${ }_{\text {free }}$ and CsCatD2 $2_{\text {bound }}$ were constructed using Yet Another Scientific Artificial Reality Application (YASARA) Structure v21.6.17 [40] as described by Kang et al. [23]. A hybrid homology model was chosen by combining the best scoring parts of the reliable models for CsCatD2 free and CsCatD2 ${ }_{\text {bound }}$ based on the experimental X-ray-characterized structures of free cathepsin D (PDB code: $5 \mathrm{n} 7 \mathrm{n}$ ) and inhibitor-bound cathepsin D (PDB code: $5 \mathrm{n} 7 \mathrm{q}$ ) from the tick I. ricinus [28]. The qualities of all models were further evaluated using the Ramachandran plot [41], ERRAT [42], and protein structure analysis (ProSA) [43]. The secondary structure elements were predicted using DSSP (https://swift.cmbi.umcn.nl/gv/dssp/; accessed on 10 August 2021).

\subsection{Structural Comparison}

Structural superpositions were carried out using TM-align [44] with default parameters and the "cealign" method script (https:/ / pymolwiki.org/index.php/Cealign; accessed on 10 August 2021). The TM-score, calculated by TM-align, indicates the fold similarity between the two structures. All structure graphics were prepared using PyMOL (PyMOL Molecular Graphics System, v2.4.1, Schrödinger, LLC, New York, NY, USA).

\subsection{Simulation}

All MD simulations were performed using a pre-installed "md_runfast.mcr" macro file within the YASARA Structure v21.6.17 [45] for both the free and bound forms of CsCatD2. All simulations were carried out on a custom-built workstation running Linux Mint 20.1 Ulyssa with Intel Core i7-10700F CPU $\times 8$ (2.9 GHz), random access memory (RAM) of $32 \mathrm{~Gb}$ and a graphic processor unit (GPU) of Nvidia GeForce RTX 3090 (24 Gb). The AMBER14 force field was applied under periodic boundary conditions. The simulation cell was allowed to include $20 \AA$ A surrounding the protein and filled with water, as a solvent, at a density of $0.997 \mathrm{~g} / \mathrm{mL}$. The initial energy minimization was carried out under relaxed constraints using steepest descent minimization in vacuo. To mimic the physiological conditions as previously described $[29,30,46]$, all simulated systems were maintained at $\mathrm{pH} 4$ or $\mathrm{pH} 7$ by adding counter ions to replace the water containing $0.9 \%$ sodium chloride $(\mathrm{NaCl})$. Simulations were performed in water at a temperature of $298 \mathrm{~K}$ at constant pressure. The cut-off radius for long-range electrostatics was set to $8 \AA$. The snapshots were saved at 250 picoseconds (ps) intervals for the duration of the 50-ns simulation, as previously suggested [31,32,47].

\subsection{Post-MD Analysis}

Subsequently, snapshots were analyzed using the customized "md_analyze.mcr" and the built-in "md_analyzeres.mcr" macro files within the YASARA package for the RMSD, RMSF, Rg, SASA, and flap parameters, such as the distance $d_{1}\left(\mathrm{Gly}_{79}-\mathrm{Met}_{297}\right)$ between the flap tip and hinge residue, TriC $\alpha$ angles $\theta_{1}\left(\mathrm{Gly}_{79}-\mathrm{Asp}_{33}-\mathrm{Met}_{297}\right)$ and $\theta_{2}\left(\mathrm{Gly}_{79}-\mathrm{Asp}_{219}-\right.$ $\mathrm{Met}_{297}$ ) for the conformational changes of the active site, and the dihedral angle $\phi$ (Gly (19- $^{-}$ Asp $_{33}-$ Asp $_{219}-$ Met $_{297}$ ) for the twisting motion of the binding pocket. The sim format was converted into xtc format using "md_convert.mcr" macro file and, subsequently, into dcd format using Wordom v0.22-rc3 [48]. DCCM and PCA were conducted using the Bio3d package v2.4-2 [49] of R Studio v1.4.1717. Plots were generated using DataGraph v4.7.1 (Visual Data Tools Inc., Chapel Hill, NC, USA) and R Studio.

\section{Conclusions}

Parasitic CatD homologues have gained significant attention for being attractive targets for therapeutic drug design as CatD plays a critical role in the degradation of blood 
to facilitate the survival of the parasite. Here, we report the $\mathrm{pH}$-dependent structure and flap dynamics of CsCatD2 from the blood-feeding parasite C. sinensis, which can cause foodborne parasitic infection and cholangiocarcinoma. The structure-inhibition relationships and validated computational simulations determined in this study will provide important insights into the binding mechanisms of parasitic CatD to potential inhibitors during the $\mathrm{pH}$ shift. Especially, acidification of 30-36-ns simulation showed significant contribution to establishment of rigid $\beta$-sheets and higher occupancy of hydrogen bonds near the catalytic residue Asp 219 , thereby enabling increased stabilization of the CsCatD2-inhibtor complex. Further, in vitro and in vivo experiments are strongly needed to confirm the structure-function and inhibition.

Supplementary Materials: The following are available online at https:/ / www.mdpi.com/article / 10.3390/pathogens10091128/s1, Table S1: Fluctuations of distance d1 of free and bound CsCatD2 at acidic and neutral conditions during 50-ns MD simulations, Table S2: Conformational states of free and bound CsCatD2 at acidic and neutral conditions, Figure S1: Quality verification of tertiary model of CsCatD2free, Figure S2: Quality verification of tertiary model of CsCatD2bound, Figure S3: Contribution of each residue of CsCatD2 to the PC1 (a) and PC2 (b), Figure S4: Snapshots of CsCatD2free at pH 4 at different time-points 32.0, 33.50, 34.25, and 45.50 ns, Figure S5: Variations of the number of hydrogen bonds through the course of 50-ns MD simulation, Figure S6: Superposed results between CsCatD2free and IrCatD1 (PDB code: 5n7n), Data S1: Major structural snapshots and their coordinates of homology models of CsCatD2free and CsCatD2bound at different time-points 0, $10,20,30,40$, and $50 \mathrm{~ns}$.

Author Contributions: Conception and design, B.-K.N., W.G.Y.; methodology and data analysis, J.-M.K., W.G.Y.; data curation and interpretation, W.G.Y., J.-M.K. and H.G.L.; writing, J.-M.K. and W.G.Y.; review and editing, B.-K.N. and W.G.Y.; supervision, B.-K.N. and W.G.Y. All authors have read and agreed to the published version of the manuscript.

Funding: This research was supported by the National Research Foundation of Korea (NRF) funded by the Ministry of Science, ICT \& Future Planning (grant no. NRF2016R1C1B1009348 and NRF2018R1C1B6005581) and Institute of Health Sciences of Gyeongsang National University (IHS GNU-2021-03).

Institutional Review Board Statement: Not applicable.

Informed Consent Statement: Not applicable.

Data Availability Statement: All data generated or analyzed during this study are included in this published article.

Acknowledgments: We gratefully thank Elmar Krieger at the YASARA Biosciences GmbH (http: / / www.yasara.org; Vienna, Austria; accessed on 22 May 2020) for technical help about post-molecular dynamics analysis and also for his fruitful advice about data interpretation.

Conflicts of Interest: The authors declare no conflict of interest.

\section{References}

1. Lun, Z.R.; Gasser, R.B.; Lai, D.H.; Li, A.X.; Zhu, X.Q.; Yu, X.B.; Fang, Y.Y. Clonorchiasis: A key foodborne zoonosis in China. Lancet Infect. Dis. 2005, 5, 31-41. [CrossRef]

2. Na, B.K.; Pak, J.H.; Hong, S.J. Clonorchis sinensis and clonorchiasis. Acta Trop. 2020, 203, 105309. [CrossRef]

3. Choi, B.I.; Han, J.K.; Hong, S.T.; Lee, K.H. Clonorchiasis and cholangiocarcinoma: Etiologic relationship and imaging diagnosis. Clin. Microbiol. Rev. 2004, 17, 540-552. [CrossRef] [PubMed]

4. Vennervald, B.J.; Polman, K. Helminths and malignancy. Parasite Immunol. 2009, 31, 686-696. [CrossRef] [PubMed]

5. Bouvard, V.; Baan, R.; Straif, K.; Grosse, Y.; Secretan, B.; El Ghissassi, F.; Benbrahim-Tallaa, L.; Guha, N.; Freeman, C.; Galichet, L.; et al. A review of human carcinogens-Part B: Biological agents. Lancet Oncol. 2009, 10, 321-322. [CrossRef]

6. Delcroix, M.; Sajid, M.; Caffrey, C.R.; Lim, K.C.; Dvorak, J.; Hsieh, I.; Bahgat, M.; Dissous, C.; McKerrow, J.H. A multienzyme network functions in intestinal protein digestion by a platyhelminth parasite. J. Biol. Chem. 2006, 281, 39316-39329. [CrossRef]

7. Sajid, M.; McKerrow, J.H. Cysteine proteases of parasitic organisms. Mol. Biochem. Parasitol. 2002, 120, 1-21. [CrossRef]

8. Na, B.K.; Kim, S.H.; Lee, E.G.; Kim, T.S.; Bae, Y.A.; Kang, I.; Yu, J.R.; Sohn, W.M.; Cho, S.Y.; Kong, Y. Critical roles for excretorysecretory cysteine proteases during tissue invasion of Paragonimus westermani newly excysted metacercariae. Cell. Microbiol. 2006, 8, 1034-1046. [CrossRef] 
9. Na, B.K.; Kang, J.M.; Sohn, W.M. CsCF-6, a novel cathepsin F-like cysteine protease for nutrient uptake of Clonorchis sinensis. Int. J. Parasitol. 2008, 38, 493-502. [CrossRef] [PubMed]

10. Robinson, M.W.; Dalton, J.P.; Donnelly, S. Helminth pathogen cathepsin proteases: It's a family affair. Trends Biochem. Sci. 2008, 33, 601-608. [CrossRef]

11. Pearson, M.S.; Ranjit, N.; Loukas, A. Blunting the knife: Development of vaccines targeting digestive proteases of blood-feeding helminth parasites. Biol. Chem. 2010, 391, 901-911. [CrossRef] [PubMed]

12. Cwiklinski, K.; Donnelly, S.; Drysdale, O.; Jewhurst, H.; Smith, D.; De Marco Verissimo, C.; Pritsch, I.C.; O’Neill, S.; Dalton, J.P.; Robinson, M.W. The cathepsin-like cysteine peptidases of trematodes of the genus Fasciola. Adv. Parasitol. 2019, 104, 113-164.

13. Horn, M.; Fajtova, P.; Rojo Arreola, L.; Ulrychova, L.; Bartosova-Sojkova, P.; Franta, Z.; Protasio, A.V.; Opavsky, D.; Vondrasek, J.; McKerrow, J.H.; et al. Trypsin- and Chymotrypsin-like serine proteases in Schistosoma mansoni-'The undiscovered country'. PLoS Negl. Trop. Dis. 2014, 8, e2766. [CrossRef] [PubMed]

14. Kang, J.M.; Ju, H.L.; Ju, J.W.; Sohn, W.M.; Kim, T.S.; Bahk, Y.Y.; Hong, S.J.; Na, B.K. Comparative biochemical and functional properties of two leucine aminopeptidases of Clonorchis sinensis. Mol. Biochem. Parasitol. 2012, 182, 17-26. [CrossRef]

15. Williamson, A.L.; Brindley, P.J.; Abbenante, G.; Datu, B.J.; Prociv, P.; Berry, C.; Girdwood, K.; Pritchard, D.I.; Fairlie, D.P.; Hotez, P.J.; et al. Hookworm aspartic protease, Na-APR-2, cleaves human hemoglobin and serum proteins in a host-specific fashion. J. Infect. Dis. 2003, 187, 484-494. [CrossRef] [PubMed]

16. Caffrey, C.R.; Placha, L.; Barinka, C.; Hradilek, M.; Dostal, J.; Sajid, M.; McKerrow, J.H.; Majer, P.; Konvalinka, J.; Vondrasek, J. Homology modeling and SAR analysis of Schistosoma japonicum cathepsin D (SjCD) with statin inhibitors identify a unique active site steric barrier with potential for the design of specific inhibitors. Biol. Chem. 2005, 386, 339-349. [CrossRef]

17. Sojka, D.; Hartmann, D.; Bartosova-Sojkova, P.; Dvorak, J. Parasite Cathepsin D-Like Peptidases and Their Relevance as Therapeutic Targets. Trends Parasitol. 2016, 32, 708-723. [CrossRef]

18. Dougall, A.M.; Skwarczynski, M.; Khoshnejad, M.; Chandrudu, S.; Daly, N.L.; Toth, I.; Loukas, A. Lipid core peptide targeting the cathepsin D hemoglobinase of Schistosoma mansoni as a component of a schistosomiasis vaccine. Hum. Vaccin. Immunother. 2014, 10, 399-409. [CrossRef]

19. Hartman, A.M.; Mondal, M.; Radeva, N.; Klebe, G.; Hirsch, A.K. Structure-Based Optimization of Inhibitors of the Aspartic Protease Endothiapepsin. Int. J. Mol. Sci. 2015, 16, 19184-19194. [CrossRef] [PubMed]

20. Brinkworth, R.I.; Prociv, P.; Loukas, A.; Brindley, P.J. Hemoglobin-degrading, aspartic proteases of blood-feeding parasites: Substrate specificity revealed by homology models. J. Biol. Chem. 2001, 276, 38844-38851. [CrossRef]

21. Li, J.; Chi, Z.; Liu, Z.; Yue, L.; Peng, Y.; Wang, L. Cloning and characterization of a novel aspartic protease gene from marinederived Metschnikowia reukaufii and its expression in E. coli. Appl. Biochem. Biotechnol. 2009, 159, 119-132. [CrossRef]

22. Williamson, A.L.; Brindley, P.J.; Loukas, A. Hookworm cathepsin D aspartic proteases: Contributing roles in the host-specific degradation of serum proteins and skin macromolecules. Parasitology 2003, 126, 179-185. [CrossRef] [PubMed]

23. Kang, J.M.; Yoo, W.G.; Le, H.G.; Thai, T.L.; Hong, S.J.; Sohn, W.M.; Na, B.K. Partial Characterization of Two Cathepsin D Family Aspartic Peptidases of Clonorchis sinensis. Korean J. Parasitol. 2019, 57, 671-680. [CrossRef]

24. Boehr, D.D.; D'Amico, R.N.; O'Rourke, K.F. Engineered control of enzyme structural dynamics and function. Protein Sci. 2018, 27, 825-838. [CrossRef] [PubMed]

25. McGillewie, L.; Ramesh, M.; Soliman, M.E. Sequence, Structural Analysis and Metrics to Define the Unique Dynamic Features of the Flap Regions Among Aspartic Proteases. Protein J. 2017, 36, 385-396. [CrossRef]

26. Berman, H.M.; Westbrook, J.; Feng, Z.; Gilliland, G.; Bhat, T.N.; Weissig, H.; Shindyalov, I.N.; Bourne, P.E. The Protein Data Bank. Nucleic Acids Res. 2000, 28, 235-242. [CrossRef]

27. Marciniszyn, J., Jr.; Hartsuck, J.A.; Tang, J. Mode of inhibition of acid proteases by pepstatin. J. Biol. Chem. 1976, 251, 7088-7094. [CrossRef]

28. Hanova, I.; Brynda, J.; Houstecka, R.; Alam, N.; Sojka, D.; Kopacek, P.; Maresova, L.; Vondrasek, J.; Horn, M.; Schueler-Furman, O.; et al. Novel Structural Mechanism of Allosteric Regulation of Aspartic Peptidases via an Evolutionarily Conserved Exosite. Cell Chem. Biol. 2018, 25, 318-329.e4. [CrossRef]

29. Mancilla-Olea, M.I.; Ortega-Lopez, J.; Figueroa-Angulo, E.E.; Avila-Gonzalez, L.; Cardenas-Guerra, R.E.; Miranda-Ozuna, J.F.T.; Gonzalez-Robles, A.; Hernandez-Garcia, M.S.; Sanchez-Ayala, L.; Arroyo, R. Trichomonas vaginalis cathepsin D-like aspartic proteinase (Tv-CatD) is positively regulated by glucose and degrades human hemoglobin. Int. J. Biochem. Cell Biol. 2018, 97, 1-15. [CrossRef]

30. Minarowska, A.; Gacko, M.; Karwowska, A.; Minarowski, L. Human cathepsin D. Folia HistoChem. CytoBiol. 2008, 46, 23-38. [CrossRef]

31. Karubiu, W.; Bhakat, S.; McGillewie, L.; Soliman, M.E. Flap dynamics of plasmepsin proteases: Insight into proposed parameters and molecular dynamics. Mol. Biosyst. 2015, 11, 1061-1066. [CrossRef]

32. Arodola, O.A.; Soliman, M.E. Molecular Dynamics Simulations of Ligand-Induced Flap Conformational Changes in Cathepsin-DA Comparative Study. J. Cell Biochem. 2016, 117, 2643-2657. [CrossRef]

33. Berjanskii, M.V.; Wishart, D.S. A simple method to predict protein flexibility using secondary chemical shifts. J. Am. Chem. Soc. 2005, 127, 14970-14971. [CrossRef] 
34. Dostal, J.; Pecina, A.; Hruskova-Heidingsfeldova, O.; Mareckova, L.; Pichova, I.; Rezacova, P.; Lepsik, M.; Brynda, J. Atomic resolution crystal structure of Sapp2p, a secreted aspartic protease from Candida parapsilosis. Acta Crystallogr. D Biol. Crystallogr. 2015, 71, 2494-2504. [CrossRef]

35. Masa, M.; Maresova, L.; Vondrasek, J.; Horn, M.; Jezek, J.; Mares, M. Cathepsin D propeptide: Mechanism and regulation of its interaction with the catalytic core. Biochemistry 2006, 45, 15474-15482. [CrossRef]

36. Lee, A.Y.; Gulnik, S.V.; Erickson, J.W. Conformational switching in an aspartic proteinase. Nat. Struct. Biol. 1998, 5, 866-871. [CrossRef]

37. Lobanov, M.; Bogatyreva, N.S.; Galzitskaia, O.V. [Radius of gyration is indicator of compactness of protein structure]. Mol. Biol. 2008, 42, 701-706. [CrossRef]

38. Richmond, T.J. Solvent accessible surface area and excluded volume in proteins. Analytical equations for overlapping spheres and implications for the hydrophobic effect. J. Mol. Biol. 1984, 178, 63-89. [CrossRef]

39. Kumalo, H.M.; Soliman, M.E. A comparative molecular dynamics study on BACE1 and BACE2 flap flexibility. J. Recept. Signal. Transduct. Res. 2016, 36, 505-514. [CrossRef] [PubMed]

40. Krieger, E.; Nabuurs, S.B.; Vriend, G. Homology modeling. Methods Biochem. Anal. 2003, 44, 509-523.

41. Lovell, S.C.; Davis, I.W.; Arendall, W.B., 3rd; de Bakker, P.I.; Word, J.M.; Prisant, M.G.; Richardson, J.S.; Richardson, D.C. Structure validation by Calpha geometry: Phi, psi and Cbeta deviation. Proteins 2003, 50, 437-450. [CrossRef]

42. Colovos, C.; Yeates, T.O. Verification of protein structures: Patterns of nonbonded atomic interactions. Protein Sci. 1993, 2 , 1511-1519. [CrossRef] [PubMed]

43. Wiederstein, M.; Sippl, M.J. ProSA-web: Interactive web service for the recognition of errors in three-dimensional structures of proteins. Nucleic Acids Res. 2007, 35, W407-W410. [CrossRef] [PubMed]

44. Zhang, Y.; Skolnick, J. TM-align: A protein structure alignment algorithm based on the TM-score. Nucleic Acids Res. 2005, 33, 2302-2309. [CrossRef] [PubMed]

45. Krieger, E.; Vriend, G. New ways to boost molecular dynamics simulations. J. Comput. Chem. 2015, 36, 996-1007. [CrossRef] [PubMed]

46. Mukherjee, B.; Tessaro, F.; Vahokoski, J.; Kursula, I.; Marq, J.B.; Scapozza, L.; Soldati-Favre, D. Modeling and resistant alleles explain the selectivity of antimalarial compound 49c towards apicomplexan aspartyl proteases. EMBO J. 2018, 37, e98047. [CrossRef]

47. McGillewie, L.; Soliman, M.E. Flap flexibility amongst plasmepsins I, II, III, IV, and V: Sequence, structural, and molecular dynamics analyses. Proteins 2015, 83, 1693-1705. [CrossRef] [PubMed]

48. Seeber, M.; Felline, A.; Raimondi, F.; Muff, S.; Friedman, R.; Rao, F.; Caflisch, A.; Fanelli, F. Wordom: A user-friendly program for the analysis of molecular structures, trajectories, and free energy surfaces. J. Comput Chem. 2011, 32, 1183-1194. [CrossRef]

49. Grant, B.J.; Rodrigues, A.P.; ElSawy, K.M.; McCammon, J.A.; Caves, L.S. Bio3d: An R package for the comparative analysis of protein structures. Bioinformatics 2006, 22, 2695-2696. [CrossRef] 